\title{
Shared meals among young adults are associated with better diet quality and predicted by family meal patterns during adolescence
}

\author{
Nicole Larson ${ }^{1, *}$, Jayne Fulkerson ${ }^{2}$, Mary Story ${ }^{1}$ and Dianne Neumark-Sztainer ${ }^{1}$ \\ 'Division of Epidemiology and Community Health, School of Public Health, University of Minnesota, \\ 1300 South Second Street, Suite 300, Minneapolis, MN 55454, USA: ${ }^{2}$ School of Nursing, \\ University of Minnesota, Minneapolis, MN, USA
}

Submitted 17 November 2011: Final revision received 15 May 2012: Accepted 17 June 2012: First published online 3 August 2012

\begin{abstract}
Objective: To describe shared meal patterns and examine associations with dietary intake among young adults.

Design: Population-based, longitudinal cohort study (Project EAT: Eating and Activity in Teens and Young Adults).

Setting: Participants completed surveys and FFQ in high-school classrooms in Minneapolis/St. Paul, MN, USA in 1998-1999 (mean age $=15 \cdot 0$ years, 'adolescence') and follow-up measures online or by mail in 2008-2009 (mean age $=25 \cdot 3$ years, 'young adulthood').

Subjects: There were 2052 participants who responded to the 10-year follow-up survey and reported on frequency of having shared meals.

Results: Among young adults, the frequency of shared meals during the past week was as follows: never (9.9\%), one or two times $(24 \cdot 7 \%)$, three to six times $(39 \cdot 1 \%)$ and seven or more times $(26 \cdot 3 \%)$. Having more frequent family meals during adolescence predicted a higher frequency of shared meals in young adulthood above and beyond other relevant sociodemographic factors such as household composition and parental status. Compared with young adults who never had family meals during adolescence, those young adults who reported seven or more family meals per week during adolescence had an average of one additional shared meal per week. Having more frequent shared meals in young adulthood was associated with greater intake of fruit among males and females, and with higher intakes of vegetables, milk products and some key nutrients among females.

Conclusions: Nutrition professionals should encourage families of adolescents to share meals often and establish the tradition of eating together, and work with young adults to ensure that healthy food and beverage choices are offered at mealtimes.
\end{abstract}

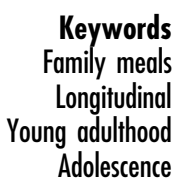

When families regularly eat together at mealtimes, children and adolescents are more likely to have diets of higher nutritional quality. Several studies have found that children and adolescents who have more family meals each week have higher intakes of fruit, vegetables and key nutrients (e.g. fibre, $\mathrm{Ca}, \mathrm{Fe}$ and several vitamins) and lower intakes of soft drinks and saturated fat ${ }^{(1-8)}$. However, to the best of the authors' knowledge, no prior research has explored whether young people who participate in family meals during adolescence carry on the tradition of shared mealtimes by regularly eating with family or other household members as they transition to adulthood and enter parenthood. Further, little is known regarding the relationship between having shared mealtimes and dietary intake in young adult populations. hood for optimal health and weight management ${ }^{(9)}$, most young adults fail to meet recommendations for healthy eating such as the Dietary Guidelines for Americans ${ }^{(10)}$. National survey data indicate that intakes of fruit, vegetables, whole grains and several vitamins and minerals are lower than recommended and nearly all US young adults exceed the recommended maximum energy intake from solid fats, added sugars and alcoholic beverages ${ }^{(11-13)}$. There is also evidence, although limited, suggesting that young adult parents may have poorer dietary intake patterns than those without children ${ }^{(14)}$. A better understanding of shared meal patterns among young adults could help inform the design of programmes and services aimed to promote improved dietary intake in this population.
While dietary intake quality is important in young adult- 
Therefore, the current study was designed to provide more information on shared meal patterns among a diverse population of young adults, including those who are parents. The first aim of the study was to describe and examine sociodemographic differences in the frequency of having shared meals among young adults as well as longitudinal associations with frequency of eating family meals during adolescence. In addition, the study aimed to examine associations between shared meal frequency in young adulthood and measures of dietary quality in the overall sample and in a subset of young adult parents.

\section{Methods}

\section{Study design and population}

Data for the present analysis were drawn from Project EAT (Eating and Activity in Teens and Young Adults), a 10-year longitudinal study designed to examine dietary intake, physical activity, weight control behaviours, weight status and factors associated with these outcomes among young people. The overall analytic sample represents 2052 participants (45\% male, 55\% female, mean age $=25 \cdot 3(\mathrm{sD} 1 \cdot 7)$ years, range $=20-31$ years $)$, including 314 custodial parents, who responded to the 10-year follow-up survey and reported on the frequency of eating with family or other household members. At baseline (Project EAT-I), junior and senior high-school students at thirty-one public schools in the Minneapolis/ St. Paul metropolitan area of Minnesota completed surveys and anthropometric measures during the 1998-1999 academic year $^{(15,16)}$. The 10-year follow-up survey (Project EAT-III) was designed to follow up on the original participants in 2008-2009 as they progressed from adolescence to young adulthood and through their twenties.

At follow-up, participants were mailed survey invitation letters providing the web address and a unique password for completing the Project EAT-III survey and an FFQ online ${ }^{(17)}$. Data collection ran from November 2008 to October 2009 and was conducted by the Health Survey Research Center in the School of Public Health at the University of Minnesota, Minneapolis, MN, USA. Among those who could be contacted at the 10-year follow-up, the response rate was $66 \cdot 4 \%$ ( $48 \cdot 2 \%$ of the original schoolbased sample). The University of Minnesota's Institutional Review Board approved all protocols used in Project EAT at each time point.

\section{Survey development}

At both time points, survey development was guided by a theoretical framework, literature reviews, expert review by professionals from different disciplines and pilot testing. The theoretical framework used to guide development of the EAT-I survey was based on social cognitive theory ${ }^{(18)}$; this framework was integrated with an ecological perspective $^{(19,20)}$ at EAT-III given the growing body of research that indicates it is important to consider not only the characteristics of individuals and their families, but also to examine characteristics of broader environments ${ }^{(21-23)}$. Age-appropriate measures of shared mealtimes were included on the EAT-I and EAT-III surveys. Because formative focus groups with adolescents at baseline emphasized the importance of eating with family members, the EAT-I survey included questions on 'family meals, ${ }^{(24)}$. However, pilot testing of the EAT-III survey in young adult focus groups revealed the importance of more broadly assessing 'shared meals' with family or other household members in young adult populations due the greater diversity of living situations during this life stage $^{(25)}$. Test-retest reliability was assessed in a diverse adolescent sample $(n 161)$ at EAT-I ${ }^{(16,26)}$ and examined in a sample of sixty-six young adults at EAT-III ${ }^{(25)}$. Details of the survey development process at both time points have been described elsewhere ${ }^{(24,25,27)}$.

\section{Shared/family meals}

At baseline, family meal frequency during adolescence was assessed with the question: 'During the past seven days, how many times did all, or most, of your family living in your house eat a meal together?' (test-retest $r=0 \cdot 70$ ). At follow-up, the frequency of having shared meals in adulthood was assessed with the slightly modified and more developmentally appropriate question: 'During the past seven days, how many times did all, or most, of the people living in your household eat a meal together?' (test-retest $r=0 \cdot 83$ ). Response categories for both questions were 'never', 'one to two times', 'three to four times', 'five to six times', seven times' and 'more than seven times'. For some of the analyses, the categories were collapsed into 'never', 'one to two times', 'three to six times' and 'seven or more times' to avoid small numbers and ease interpretation. At follow-up, young adults were also given the option of skipping the question by indicating 'I live alone' and those who indicated living alone were excluded from the current analysis ( $n 221$ ). To allow for comparison of mean meal frequencies, the number of meals was assigned a score of $0,1 \cdot 5,3 \cdot 5,5 \cdot 5,7$ or 10 to correspond to the six possible responses.

\section{Diet quality}

A semi-quantitative FFQ assessing intake of multivitamins, twenty-seven other dietary supplements (e.g. Ca, vitamin C, folic acid) and 151 foods was administered at the same time as the Project EAT-III survey ${ }^{(28)}$. This FFQ was used to measure usual past-year intake of fruit (excluding juice), vegetables (excluding potatoes), milk products, whole grains and sugar-sweetened beverages for the current study ${ }^{(28)}$. A daily serving was defined as the equivalent of one-half cup for fruit and vegetables, $16 \mathrm{~g}$ for whole grains and one cup for milk products. For sugar-sweetened beverages, a serving was defined as the equivalent of one glass, bottle or can. In addition, the FFQ 
was used to assess usual daily intakes of total energy (kJ or kcal), total fat (percentage of total energy), saturated fat (percentage of total energy), alcohol (percentage of total energy), $\mathrm{Na}$ (mg), fibre (g), Ca (mg), Fe (mg), K $(\mathrm{mg})$ and folate $(\mu \mathrm{g})$. Dietary intake outcomes were selected for consideration with an emphasis on foods and nutrients identified to be of public health concern in the Dietary Guidelines for Americans, 2010 or of particular relevance to reproductive health in young adulthood (e.g. folate, Fe $)^{(10,29)}$. Although other food (e.g. meats, snack foods) and nutrient intake measures (e.g. Zn, vitamin C) were available for consideration, a limited number of specific dietary outcomes were selected to allow for the development of specific and tailored messages based on the results. Nutrient intakes were determined in 2009 by the Nutrition Questionnaire Service Center at the Harvard School of Public Health using a specially designed database, primarily based on the US Department of Agriculture's Nutrient Database for Standard Reference (release 19) ${ }^{(30)}$. Intakes of foods and nutrients respectively were compared with intakes recommended in the Dietary Guidelines for Americans, 2010 ${ }^{(10)}$ and the Institute of Medicine's Dietary Reference Intakes ${ }^{(31-35)}$. Previous studies have examined and reported on the reliability and validity of intake estimates ${ }^{(36,37)}$. Responses to the FFQ were excluded for 127 participants who reported a biologically implausible level of total energy intake $(<2093 \mathrm{~kJ} / \mathrm{d}$ or $>20934 \mathrm{~kJ} / \mathrm{d})$ and for thirty-seven participants who left more than twenty items blank ${ }^{(38)}$.

\section{Sociodemographic characteristics}

Sociodemographic characteristics were self-reported and included gender, age, race/ethnicity, educational attainment, current employment, living situation and parental status. Educational attainment was assessed at follow-up with the question: 'What is the highest level of education that you have completed?' (test-retest agreement $=97 \%$ ). Responses were categorized according to whether young adults had completed some high school, a high-school degree or a General Equivalency Diploma, a 2-year postsecondary degree or a 4-year post-secondary degree. Current employment was assessed with the question: 'How many hours a week do you currently work for pay?' (test-retest $r=0 \cdot 94$ ). Young adults who reported working $\geq 40 \mathrm{~h} /$ week were categorized as employed full-time. Living situation was assessed with the question: 'During the past year, with whom did you live the majority of the time?' (test-retest agreement $=100 \%$ ).

Parental status was assessed by asking young adults, 'How many children do you have (including step-children and adopted children)?' (test-retest agreement $=100 \%$ ) Response options ranged from 'none' to 'three or more'. Those who reported having one or more child were asked to write their ages in years. Only those who reported living with their child(ren) for the majority of the time during the past year were defined as parents for the analyses reported here. Among custodial parents, the mean age of the oldest child was 5 years. To best capture family meals involving children, analyses examining the relationship between shared meal frequency and diet quality focused on custodial parents with at least one child aged 6 months or older (97.6\%). Parents who reported only having children less than 6 months old were not included in analyses because it is recommended that parents wait to start feeding children solid foods until they reach 4 to 6 months of age ${ }^{(39)}$.

\section{Statistical analyses}

Descriptive statistics were calculated to examine associations between sociodemographic characteristics and shared meal patterns during young adulthood. The $\chi^{2}$ test was used to test for independence of sociodemographic categorization and frequency of shared meals in the past week. Linear regression models were used to further examine adjusted differences in the frequency of shared meals according to sociodemographic characteristics and longitudinal associations with family meal frequency during adolescence. An initial model included all sociodemographic factors found to be related to shared meal patterns in the unadjusted analysis described above along with race/ethnicity; race/ethnicity was included in the model as a strong association with family meal frequency was found in a previously published analysis using only the baseline Project EAT-I data ${ }^{(8)}$. Then a second model was examined, including all of the sociodemographic factors in the initial model and family meal frequency at baseline.

Finally, gender-stratified linear regression analysis was conducted to examine associations between shared meal frequency in young adulthood and dietary intake outcomes. Based on prior longitudinal research using the Project EAT data that indicated more frequent family meals during adolescence predicts higher priority for eating with family and friends and better diet quality during the transition to adulthood $^{(40)}$, associations between shared meal frequency and dietary patterns of young adults were examined with and without adjustment for family meal frequency in adolescence. As the results were similar with and without adjustment, only the associations from models which accounted for family meal frequency in adolescence are described in detail here. One model of associations with dietary intake outcomes accounted for sociodemographic factors and baseline family meal frequency, and a second model additionally accounted for total energy intake using the nutrient density approach ${ }^{(41)}$. Only means from the first model were included here as these values representing total daily intake were more readily interpretable than the outcome of daily intake per $4184 \mathrm{~kJ}$ from the second model. Probability testing of trends in the dietary intake outcome variables across shared meal frequency categories used linear contrasts. 
In all analyses, the data were weighted using the response propensity method because attrition from the baseline sample (1998-1999) did not occur at random. Compared with the baseline sample, EAT-III participants were more likely to be female, white and of higher socioeconomic status based on level of parental education reported at EAT-I. The response propensity method applies a weight equal to the inverse of the estimated probability that an individual responded in 2008-2009 and produces estimates representative of the demographic makeup of the baseline Project EAT-I sample, thereby allowing results to be more fully generalizable to the population of young people in the Minneapolis/ St. Paul metropolitan area ${ }^{(42)}$. Weights were additionally calibrated so that the weighted total sample sizes used in analyses accurately reflect the actual observed sample sizes for men and women. The weighted sample was $46.9 \%$ white, $18.9 \%$ African American, 20.5\% Asian and $13.7 \%$ mixed or other race/ethnicity. A $95 \%$ confidence level was used to interpret the statistical significance of probability tests, corresponding to $P<0 \cdot 05$. Whenever the dependent variable exhibited positive skewness, such testing was carried out under the square root transformation. Analyses were conducted using the SAS statistical software package version 9.2 (2008; SAS Institute).

\section{Results}

\section{Shared meals among young adults by sociodemographic characteristics}

In the overall sample of young adults, the unadjusted frequency of shared meals during the past week at follow-up was as follows: never $(9.9 \%)$, one or two times $(24 \cdot 7 \%)$, three to six times $(39 \cdot 1 \%)$ and seven or more times $(26 \cdot 3 \%)$. However, frequency of shared meals differed according to gender, age, employment status, parental status and living situations of young adults (all $P \leq 0 \cdot 001$; Table 1 ). The groups most likely to have shared meals seven or more times per week were females, young adults aged 26-31 years, those who were not employed, those who were parents and those living with a spouse or partner.

Similar patterns were observed in a multivariate model including gender, age, race, parental status and other sociodemographic characteristics related to shared meal frequency in the univariate analysis (Table 2, Model 1). Although differences by age observed in the univariate analysis did not remain statistically significant, mean shared meal frequencies were likewise highest among females $(P=0 \cdot 02)$, those who were not employed $(P=0 \cdot 009)$, those who were parents $(P<0 \cdot 001)$ and those living with a spouse or partner $(P<0 \cdot 001)$. Racial/ethnic differences

Table 1 Young adults' frequency of shared meals in the past week by sociodemographic characteristics: 10-year follow-up, Project EAT (Eating and Activity in Teens and Young Adults), Minneapolis/St. Paul, MN, USA, 2008-2009

\begin{tabular}{|c|c|c|c|c|c|c|}
\hline & \multirow[b]{2}{*}{$n$} & \multicolumn{4}{|c|}{ Frequency of shared meals/week* } & \multirow[b]{2}{*}{$P$ valuet } \\
\hline & & Never (\%) & $1-2$ times $(\%)$ & 3-6 times (\%) & $7+$ times $(\%)$ & \\
\hline Gender & & & & & & $<0.001$ \\
\hline Males & 932 & $11 \cdot 9$ & $28 \cdot 7$ & $36 \cdot 4$ & $22 \cdot 9$ & \\
\hline Females & 1120 & $8 \cdot 2$ & $21 \cdot 4$ & $41 \cdot 3$ & $29 \cdot 1$ & \\
\hline Age & & & & & & $0 \cdot 001$ \\
\hline 20-25 years & 636 & $12 \cdot 1$ & $27 \cdot 3$ & $39 \cdot 3$ & $21 \cdot 3$ & \\
\hline 26-31 years & 1416 & $8 \cdot 9$ & $23 \cdot 6$ & $39 \cdot 0$ & $28 \cdot 5$ & \\
\hline Race/ethnicity & & & & & & $0 \cdot 32$ \\
\hline White & 1281 & $10 \cdot 2$ & $24 \cdot 1$ & $39 \cdot 4$ & $26 \cdot 3$ & \\
\hline Black or African American & 192 & $11 \cdot 0$ & $27 \cdot 6$ & $37 \cdot 2$ & $24 \cdot 2$ & \\
\hline Asian American & 353 & $8 \cdot 2$ & $23 \cdot 1$ & $38 \cdot 5$ & $30 \cdot 1$ & \\
\hline Mixed/other & 205 & $8 \cdot 1$ & $26 \cdot 2$ & $42 \cdot 7$ & $23 \cdot 0$ & \\
\hline Educational attainment & & & & & & 0.61 \\
\hline Some high school & 63 & $4 \cdot 8$ & $28 \cdot 4$ & $40 \cdot 3$ & $26 \cdot 4$ & \\
\hline High-school degree & 778 & $9 \cdot 8$ & $23 \cdot 8$ & $39 \cdot 8$ & $26 \cdot 6$ & \\
\hline 2-year post-secondary degree & 490 & $11 \cdot 5$ & $22 \cdot 5$ & $40 \cdot 3$ & $25 \cdot 7$ & \\
\hline 4+-year post-secondary degree & 714 & $9 \cdot 2$ & $26 \cdot 8$ & $37 \cdot 6$ & $26 \cdot 3$ & \\
\hline Employment status & & & & & & $<0 \cdot 001$ \\
\hline Not employed & 210 & $6 \cdot 7$ & $22 \cdot 2$ & $38 \cdot 3$ & $32 \cdot 8$ & \\
\hline Part-time & 687 & $10 \cdot 5$ & $27 \cdot 5$ & $41 \cdot 8$ & $20 \cdot 2$ & \\
\hline Full-time & 1056 & $10 \cdot 0$ & $23 \cdot 5$ & $38 \cdot 0$ & $28 \cdot 4$ & \\
\hline Parental status & & & & & & $<0 \cdot 001$ \\
\hline No children & 1738 & $11 \cdot 4$ & $26 \cdot 7$ & $38 \cdot 5$ & $23 \cdot 4$ & \\
\hline$\geq 1$ child & 314 & $3 \cdot 0$ & $15 \cdot 8$ & $42 \cdot 0$ & $39 \cdot 2$ & \\
\hline Live with spouse/partner & & & & & & $<0.001$ \\
\hline No & 978 & $17 \cdot 3$ & $34 \cdot 2$ & $33 \cdot 3$ & $15 \cdot 2$ & \\
\hline Yes & 1074 & $3 \cdot 0$ & $15 \cdot 8$ & $44 \cdot 5$ & $36 \cdot 7$ & \\
\hline Live with parents & & & & & & $<0.001$ \\
\hline No & 1247 & $9 \cdot 6$ & $21 \cdot 5$ & $37 \cdot 9$ & $31 \cdot 0$ & \\
\hline Yes & 603 & $12 \cdot 1$ & $32 \cdot 5$ & $39 \cdot 5$ & $15 \cdot 9$ & \\
\hline
\end{tabular}

*All percentages are weighted to reflect the probability of responding to the EAT-III survey.

$+P$ values represent testing for independence of sociodemographic categorization and frequency of shared meals in the past week by the $\chi^{2}$ test. 
Table 2 Young adults' adjusted mean frequency of shared meals in the past week by sociodemographic characteristics and frequency of family meals during adolescence: 10-year follow-up, Project EAT (Eating and Activity in Teens and Young Adults), Minneapolis/St. Paul, MN, USA, 2008-2009

\begin{tabular}{|c|c|c|c|c|c|c|}
\hline & \multicolumn{3}{|c|}{ Model $1^{\star}$} & \multicolumn{3}{|c|}{ Model $2+$} \\
\hline & $\begin{array}{l}\text { Adjusted mean } \\
\text { frequency }\end{array}$ & SE & $P$ value & $\begin{array}{l}\text { Adjusted mean } \\
\text { frequency }\end{array}$ & SE & $P$ value \\
\hline Gender & & & 0.02 & & & 0.02 \\
\hline Males & $4 \cdot 1$ & $0 \cdot 1$ & & $4 \cdot 1$ & $0 \cdot 1$ & \\
\hline Females & $4 \cdot 5$ & $0 \cdot 1$ & & $4 \cdot 4$ & $0 \cdot 1$ & \\
\hline Age & & & $0 \cdot 14$ & & & 0.01 \\
\hline $20-25$ years & $4 \cdot 1$ & $0 \cdot 1$ & & $4 \cdot 0$ & $0 \cdot 1$ & \\
\hline $26-31$ years & $4 \cdot 4$ & $0 \cdot 1$ & & $4 \cdot 4$ & $0 \cdot 1$ & \\
\hline Race & & & 0.01 & & & 0.34 \\
\hline White & $4 \cdot 3$ & $0 \cdot 1$ & & $4 \cdot 3$ & $0 \cdot 1$ & \\
\hline Black or African American & $4 \cdot 1$ & $0 \cdot 2$ & & $4 \cdot 2$ & $0 \cdot 2$ & \\
\hline Asian American & $4 \cdot 8$ & $0 \cdot 2$ & & $4 \cdot 5$ & $0 \cdot 2$ & \\
\hline Mixed/other & $4 \cdot 0$ & $0 \cdot 2$ & & $4 \cdot 1$ & $0 \cdot 2$ & \\
\hline Employment status & & & 0.009 & & & 0.02 \\
\hline Not employed & $4 \cdot 9$ & $0 \cdot 2$ & & $4 \cdot 9$ & $0 \cdot 2$ & \\
\hline Part-time & $4 \cdot 2$ & $0 \cdot 1$ & & $4 \cdot 2$ & $0 \cdot 1$ & \\
\hline Full-time & $4 \cdot 3$ & $0 \cdot 1$ & & $4 \cdot 3$ & $0 \cdot 1$ & \\
\hline Parental status & & & $<0.001$ & & & $<0.001$ \\
\hline No children & $4 \cdot 2$ & $0 \cdot 1$ & & $4 \cdot 2$ & $0 \cdot 1$ & \\
\hline$\geq 1$ child & $4 \cdot 9$ & $0 \cdot 2$ & & $4 \cdot 9$ & $0 \cdot 2$ & \\
\hline Live with spouse/partner & & & $<0.001$ & & & $<0.001$ \\
\hline No & $3 \cdot 2$ & $0 \cdot 1$ & & $3 \cdot 2$ & $0 \cdot 1$ & \\
\hline Yes & $5 \cdot 4$ & $0 \cdot 1$ & & $5 \cdot 5$ & $0 \cdot 1$ & \\
\hline Live with parents & & & $0 \cdot 67$ & & & 0.99 \\
\hline No & $4 \cdot 3$ & $0 \cdot 1$ & & $4 \cdot 3$ & $0 \cdot 1$ & \\
\hline Yes & $4 \cdot 3$ & $0 \cdot 1$ & & $4 \cdot 3$ & $0 \cdot 1$ & \\
\hline Family meals during adolescence (past $7 d$ ) & & & & & & $<0.001$ \\
\hline Never & - & - & & $3 \cdot 8$ & $0 \cdot 2$ & \\
\hline $1-2$ times & - & - & & $3 \cdot 9$ & $0 \cdot 2$ & \\
\hline 3-6 times & - & - & & $4 \cdot 3$ & $0 \cdot 1$ & \\
\hline $7+$ times & - & - & & $4 \cdot 9$ & 0.1 & \\
\hline
\end{tabular}

*Model 1 includes gender, age, race, employment status, parental status and living situation; $R^{2}=0 \cdot 16$. tModel 2 includes the covariates in Model 1 and family meal frequency at baseline (Time 1 ); $R^{2}=0 \cdot 18$.

were also observed $(P=0 \cdot 01)$, with the highest mean frequency reported by Asian-American young adults $(4 \cdot 8$ meals/week) and the lowest frequency reported by those in the mixed/other category ( $4 \cdot 0$ meals/week).

\section{Shared meals among young adults by family meal frequency during adolescence}

Frequency of shared meals in young adulthood was further examined according to frequency of family meals during adolescence (Table 2, Model 2). The longitudinal multivariate model similarly accounted for all of the same sociodemographic characteristics included in Model 1 and showed that family meal frequency during adolescence was positively associated with the frequency of shared meals in young adulthood $(P<0 \cdot 001)$. Compared with young adults who never had family meals during adolescence, those young adults who reported seven or more family meals per week during adolescence had an average of one additional shared meal per week ( $3.8 v .4 .9$ meals/week).

\section{Young adults' dietary intake by frequency of shared meals}

Associations between frequency of shared meals and dietary intake were examined in models accounting for sociodemographic characteristics and baseline family meal frequency among young adult females (Table 3, Model 1) and males (Table 4, Model 1). Frequency of shared meals was positively associated with intake of fruit among females $(P=0.03)$ and males $(P=0.004)$. Among females, frequency of shared meals was also positively associated with intakes of vegetables $(P=0 \cdot 006)$, milk products $(P=0 \cdot 008)$, energy $(P=0 \cdot 01)$, fibre $(P=0.009)$, Ca $(P=0.002)$, Fe $(P=0.02)$ and $\mathrm{K}(P<0 \cdot 001)$. Among males, frequency of shared meals was also positively associated with intake of whole grains $(P=0 \cdot 04)$.

Associations between frequency of shared meals and dietary intake were next examined in models that additionally accounted for total energy intake among females (Table 3, Model 2) and males (Table 4, Model 2). Among females, intake of $\mathrm{K}(P=0.006)$ was still significantly and positively associated with frequency of shared meals. Among males, frequency of shared meals continued to be positively associated with intake of fruit $(P=0.003)$ and statistically significant associations with higher intakes of $\mathrm{Ca}(P=0.04)$ and $\mathrm{K}(P=0.008)$ emerged. In contrast, a negative association between frequency of shared meals and intake of sugar-sweetened 
Table 3 Female young adults' adjusted mean daily food and nutrient intakes by frequency of shared meals in past the week: 10-year follow-up, Project EAT (Eating and Activity in Teens and Young Adults), Minneapolis/St. Paul, MN, USA, 2008-2009

\begin{tabular}{|c|c|c|c|c|c|c|c|c|c|c|c|}
\hline & & \multicolumn{9}{|c|}{ Model $1^{\star}$} & \multirow{3}{*}{$\frac{\text { Model } 2 \dagger}{P \text { trend } \ddagger}$} \\
\hline & & \multicolumn{2}{|c|}{ Never (n 85) } & \multicolumn{2}{|c|}{$1-2$ times ( $n$ 204) } & \multicolumn{2}{|c|}{ 3-6 times $(n 418)$} & \multicolumn{2}{|c|}{$7+$ times $(n 283)$} & \multirow[b]{2}{*}{$P$ trend $\ddagger$} & \\
\hline & & Mean & SE & Mean & SE & Mean & SE & Mean & SE & & \\
\hline Food (servings) & $\mathrm{DG}$ & & & & & & & & & & \\
\hline Fruit & $\geq 4$ & 0.99 & $0 \cdot 18$ & $1 \cdot 22$ & $0 \cdot 12$ & $1 \cdot 44$ & 0.08 & $1 \cdot 44$ & $0 \cdot 11$ & 0.03 & $0 \cdot 27$ \\
\hline Vegetables & $\geq 5$ & $2 \cdot 08$ & 0.24 & $2 \cdot \overline{11}$ & $0 \cdot 16$ & $2 \cdot 58$ & $0 \cdot 11$ & $2 \cdot 79$ & $0 \cdot 14$ & 0.006 & $0 \cdot 13$ \\
\hline Milk products & $\geq 3$ & $1 \cdot 50$ & $0 \cdot 18$ & $1 \cdot 81$ & $0 \cdot 12$ & $1 \cdot 86$ & 0.08 & $2 \cdot 08$ & $0 \cdot 10$ & 0.008 & $0 \cdot 12$ \\
\hline Whole grains & $\geq 3$ & $1 \cdot 66$ & $0 \cdot 17$ & $1 \cdot 90$ & $0 \cdot 12$ & $1 \cdot 76$ & 0.08 & $1 \cdot 97$ & $0 \cdot 10$ & $0 \cdot 19$ & 0.66 \\
\hline Sugar-sweetened beverages & NA & 0.64 & $0 \cdot 13$ & $0 \cdot 61$ & $0 \cdot 09$ & $0 \cdot 78$ & 0.06 & 0.58 & 0.07 & 0.33 & 0.03 \\
\hline Nutrients & DRI & & & & & & & & & & \\
\hline Energy (kJ) & NA & 7539 & 402 & 8221 & 276 & 8343 & 184 & 8778 & 234 & 0.01 & NA \\
\hline Energy (kcal) & NA & 1802 & 96 & 1965 & 66 & 1994 & 44 & 2098 & 56 & $0 \cdot 01$ & NA \\
\hline Energy from fat (\%) & $20-35 \%$ & $30 \cdot 6$ & $0 \cdot 7$ & $30 \cdot 6$ & 0.5 & $29 \cdot 7$ & 0.3 & 30.5 & 0.4 & 0.54 & NA \\
\hline Energy from saturated fat (\%) & $<10 \%$ & $10 \cdot 6$ & $0 \cdot 3$ & $10 \cdot 6$ & $0 \cdot 2$ & $10 \cdot 1$ & $0 \cdot 1$ & $10 \cdot 6$ & $0 \cdot 2$ & 0.79 & NA \\
\hline Energy from alcohol (\%) & NA & $2 \cdot 0$ & 0.4 & $2 \cdot 4$ & 0.3 & $2 \cdot 2$ & $0 \cdot 2$ & $2 \cdot 6$ & 0.2 & $0 \cdot 30$ & NA \\
\hline Fibre $(g)$ & 25 & $16 \cdot 8$ & $1 \cdot 3$ & $18 \cdot 8$ & 0.9 & $19 \cdot 5$ & 0.6 & $20 \cdot 9$ & $0 \cdot 7$ & 0.009 & 0.47 \\
\hline $\mathrm{Ca}(\mathrm{mg})$ & 800 & 834 & 66 & 989 & 45 & 997 & 30 & 1079 & 38 & 0.002 & $0 \cdot 13$ \\
\hline $\mathrm{Fe}(\mathrm{mg})$ & $8 \cdot 1$ & $12 \cdot 9$ & 0.8 & $15 \cdot 1$ & 0.6 & $14 \cdot 4$ & 0.4 & $15 \cdot 2$ & 0.5 & 0.02 & 0.87 \\
\hline $\mathrm{K}(\mathrm{mg})$ & 4700 & 2515 & 162 & 2845 & 111 & 2979 & 74 & 3203 & 94 & $<0.001$ & 0.006 \\
\hline Folate $(\mu \mathrm{g}) \S$ & 320 & 875 & 73 & 878 & 50 & 842 & 33 & 909 & 42 & 0.68 & $0 \cdot 27$ \\
\hline
\end{tabular}

DG, servings recommended in the Dietary Guidelines for Americans, $2010^{(10)}$ for a 8374 kJ diet; NA, not applicable; DRI, Dietary Reference Intakes ${ }^{(31-35)}$ (DRI for $\mathrm{Ca}, \mathrm{Fe}$ and folate are Estimated Average Requirements; reference values for $\mathrm{K}$ and fibre are Adequate Intakes).

*Weighted Model 1 is adjusted for age, race/ethnicity, employment status, parental status, living situation and baseline frequency of family meals.

tWeighted Model 2 is adjusted for the covariates in Model 1 and total energy intake.

$\ddagger P$ value for linear trend across categories of shared meal frequency.

$\S$ As dietary folate equivalents.

Table 4 Male young adults' adjusted mean daily food and nutrient intakes by frequency of shared meals in past the week: 10-year follow-up, Project EAT (Eating and Activity in Teens and Young Adults), Minneapolis/St. Paul, MN, USA, 2008-2009

\begin{tabular}{|c|c|c|c|c|c|c|c|c|c|c|c|}
\hline & & \multicolumn{9}{|c|}{ Model $1^{*}$} & \multirow[b]{2}{*}{ Model $2 \dagger$} \\
\hline & & \multicolumn{2}{|c|}{ Never ( $n$ 92) } & \multicolumn{2}{|c|}{$1-2$ times $(n 239)$} & \multicolumn{2}{|c|}{ 3-6 times $(n 290)$} & \multicolumn{2}{|c|}{$7+$ times $(n 187)$} & \multirow[b]{2}{*}{$P$ trend $\ddagger$} & \\
\hline & & Mean & SE & Mean & SE & Mean & SE & Mean & SE & & $P$ trend $\ddagger$ \\
\hline Food (servings) & DG & & & & & & & & & & \\
\hline Fruit & $\geq 4$ & $0 \cdot 94$ & $0 \cdot 13$ & $1 \cdot 03$ & 0.08 & 1.06 & 0.07 & $1 \cdot 32$ & 0.09 & 0.004 & 0.003 \\
\hline Vegetables & $\geq 5$ & 1.99 & $0 \cdot 21$ & $1 \cdot 79$ & $0 \cdot 13$ & $2 \cdot 18$ & $0 \cdot 12$ & $2 \cdot 46$ & $0 \cdot 16$ & 0.06 & $0 \cdot 10$ \\
\hline Milk products & $\geq 3$ & $1 \cdot 73$ & $0 \cdot 18$ & $1 \cdot 82$ & $0 \cdot 11$ & 0.96 & $0 \cdot 10$ & $2 \cdot 17$ & $0 \cdot 13$ & 0.06 & 0.08 \\
\hline Whole grains & $\geq 3$ & $1 \cdot 51$ & $0 \cdot 19$ & $1 \cdot 68$ & $0 \cdot 12$ & 0.98 & $0 \cdot 11$ & 1.97 & $0 \cdot 14$ & 0.04 & $0 \cdot 14$ \\
\hline Sugar-sweetened beverages & NA & $1 \cdot 31$ & $0 \cdot 16$ & $1 \cdot 08$ & 0.09 & $1 \cdot 06$ & 0.09 & $0 \cdot 88$ & $0 \cdot 11$ & 0.09 & 0.06 \\
\hline Nutrients & DRI & & & & & & & & & & \\
\hline Energy (kJ) & NA & 8770 & 435 & 9364 & 263 & 9719 & 238 & 8903 & 318 & 0.58 & NA \\
\hline Energy (kcal) & NA & 2096 & 104 & 2238 & 63 & 2323 & 57 & 2128 & 76 & 0.58 & NA \\
\hline Energy from fat $(\%)$ & $20-35 \%$ & $30 \cdot 4$ & 0.7 & $30 \cdot 8$ & $0 \cdot 4$ & $29 \cdot 9$ & $0 \cdot 4$ & $30 \cdot 1$ & 0.5 & 0.56 & NA \\
\hline Energy from saturated fat (\%) & $<10 \%$ & $10 \cdot 2$ & 0.3 & $10 \cdot 4$ & $0 \cdot 2$ & $10 \cdot 2$ & $0 \cdot 1$ & $10 \cdot 4$ & 0.2 & $0 \cdot 64$ & NA \\
\hline Energy from alcohol (\%) & NA & $3 \cdot 3$ & 0.5 & $4 \cdot 0$ & $0 \cdot 3$ & $3 \cdot 9$ & $0 \cdot 3$ & $3 \cdot 2$ & 0.4 & $0 \cdot 89$ & NA \\
\hline Fibre $(\mathrm{g})$ & 38 & $16 \cdot 3$ & $1 \cdot 2$ & $17 \cdot 9$ & $0 \cdot 7$ & $19 \cdot 2$ & 0.7 & $19 \cdot 4$ & $0 \cdot 9$ & 0.08 & $0 \cdot 14$ \\
\hline $\mathrm{Ca}(\mathrm{mg})$ & 800 & 922 & 67 & 990 & 41 & 1057 & 37 & 1085 & 49 & 0.05 & 0.04 \\
\hline $\mathrm{Fe}(\mathrm{mg})$ & $6 \cdot 0$ & $13 \cdot 3$ & 0.9 & $14 \cdot 6$ & 0.5 & $15 \cdot 8$ & 0.5 & $14 \cdot 9$ & 0.6 & $0 \cdot 10$ & 0.06 \\
\hline $\mathrm{K}(\mathrm{mg})$ & 4700 & 2773 & 163 & 2959 & 99 & 3181 & 89 & 3132 & 119 & 0.05 & 0.008 \\
\hline Folate $(\mu \mathrm{g}) \S$ & 320 & 663 & 53 & 683 & 32 & 766 & 29 & 763 & 39 & 0.06 & $0 \cdot 16$ \\
\hline
\end{tabular}

DG, servings recommended in the Dietary Guidelines for Americans, $2010^{(10)}$ for a 8374 kJ diet; NA, not applicable; DRI, Dietary Reference Intakes ${ }^{(31-35)}$ (DRI for $\mathrm{Ca}, \mathrm{Fe}$ and folate are Estimated Average Requirements; reference values for $\mathrm{K}$ and fibre are Adequate Intakes).

*Weighted Model 1 is adjusted for age, race/ethnicity, employment status, parental status, living situation and baseline frequency of family meals.

tWeighted Model 2 is adjusted for the covariates in Model 1 and total energy intake.

$\ddagger P$ value for linear trend across categories of shared meal frequency.

$\S$ As dietary folate equivalents.

beverages was observed among females $(P=0 \cdot 03)$ with a similar trend among males $(P=0 \cdot 06)$. All associations were similar when examined without adjustment for baseline family meal frequency; however, among males, frequency of shared meals was positively associated with intake of $\mathrm{Fe}(P=0 \cdot 03)$ and the inverse association with sugar-sweetened beverage consumption was statistically significant $(P=0 \cdot 03)$. 


\section{Young adults' dietary intake and regular shared meals among parents}

Given the high average frequency of nearly five shared meals per week among young adult parents, associations of meal frequency with dietary intake were examined by contrasting parents who reported five or more meals per week with parents who reported fewer than five meals per week. Associations between the frequency of shared meals and dietary intake were first examined in models accounting only for sociodemographic characteristics and baseline family meals among young adult parents (females: Table 5, Model 1; males: Table 6, Model 1). Among female

Table 5 Female parents' adjusted mean daily food and nutrient intakes by frequency of shared meals in past the week: 10-year follow-up, Project EAT (Eating and Activity in Teens and Young Adults), Minneapolis/St. Paul, MN, USA, 2008-2009

\begin{tabular}{|c|c|c|c|c|c|c|c|}
\hline & & \multicolumn{5}{|c|}{ Model $1^{*}$} & \multirow{3}{*}{$\frac{\text { Model } 2}{P \text { trend }}$} \\
\hline & & \multicolumn{2}{|c|}{$<5$ times $(n 72)$} & \multicolumn{2}{|c|}{$5+$ times $(n 120)$} & \multirow[b]{2}{*}{$P$ trend $\ddagger$} & \\
\hline & & Mean & SE & Mean & SE & & \\
\hline Food (servings) & DG & & & & & & \\
\hline Fruit & $\geq 4$ & $1 \cdot 02$ & 0.27 & $1 \cdot 98$ & 0.24 & 0.01 & 0.01 \\
\hline Vegetables & $\geq 5$ & $2 \cdot 16$ & 0.27 & $2 \cdot 92$ & $0 \cdot 24$ & $0 \cdot 14$ & $0 \cdot 37$ \\
\hline Milk products & $\geq 3$ & $1 \cdot 96$ & 0.22 & $1 \cdot 97$ & $0 \cdot 19$ & 0.79 & $0 \cdot 78$ \\
\hline Whole grains & $\geq 3$ & 1.52 & $0 \cdot 15$ & $1 \cdot 75$ & 0.13 & 0.23 & 0.38 \\
\hline Sugar-sweetened beverages & NA & $1 \cdot 00$ & $0 \cdot 17$ & $0 \cdot 89$ & $0 \cdot 16$ & $0 \cdot 30$ & $0 \cdot 14$ \\
\hline Nutrients & DRI & & & & & & \\
\hline Energy (kJ) & NA & 8874 & 477 & 9330 & 422 & $0 \cdot 68$ & NA \\
\hline Energy (kcal) & NA & 2121 & 114 & 2230 & 101 & 0.68 & NA \\
\hline Energy from fat (\%) & $20-35 \%$ & $31 \cdot 6$ & 0.7 & $29 \cdot 6$ & 0.6 & 0.05 & NA \\
\hline Energy from saturated fat (\%) & $<10 \%$ & $11 \cdot 3$ & $0 \cdot 3$ & $10 \cdot 5$ & $0 \cdot 3$ & $0 \cdot 10$ & NA \\
\hline Energy from alcohol (\%) & NA & 0.9 & $0 \cdot 3$ & $1 \cdot 4$ & $0 \cdot 3$ & 0.90 & NA \\
\hline Fibre $(\mathrm{g})$ & 25 & $16 \cdot 9$ & 1.5 & $21 \cdot 9$ & $1 \cdot 3$ & 0.04 & 0.02 \\
\hline $\mathrm{Ca}(\mathrm{mg})$ & 800 & 1009 & 76 & 1053 & 67 & 0.58 & 0.60 \\
\hline $\mathrm{Fe}(\mathrm{mg})$ & $8 \cdot 1$ & $14 \cdot 9$ & 0.9 & $15 \cdot 8$ & 0.8 & 0.63 & 0.94 \\
\hline $\mathrm{K}(\mathrm{mg})$ & 4700 & 2945 & 204 & 3405 & 182 & $0 \cdot 18$ & $0 \cdot 13$ \\
\hline Folate $(\mu \mathrm{g}) \S$ & 320 & 842 & 87 & 1005 & 78 & 0.23 & 0.59 \\
\hline
\end{tabular}

DG, servings recommended in the Dietary Guidelines for Americans, $2010^{(10)}$ for a $8374 \mathrm{~kJ}$ diet; NA, not applicable; DRI, Dietary Reference Intakes ${ }^{(31-35)}$ (DRI for $\mathrm{Ca}, \mathrm{Fe}$ and folate are Estimated Average Requirements; reference values for $\mathrm{K}$ and fibre are Adequate Intakes).

*Weighted Model 1 is adjusted for age, race/ethnicity, employment status, parental status, living situation and baseline frequency of family meals.

tWeighted Model 2 is adjusted for the covariates in Model 1 and total energy intake.

$\ddagger P$ value for linear trend across categories of shared meal frequency.

$\S$ As dietary folate equivalents.

Table 6 Male parents' adjusted mean daily food and nutrient intakes by frequency of shared meals in past the week: 10-year follow-up, Project EAT (Eating and Activity in Teens and Young Adults), Minneapolis/St. Paul, MN, USA, 2008-2009

\begin{tabular}{|c|c|c|c|c|c|c|c|}
\hline & & \multicolumn{5}{|c|}{ Model $1^{*}$} & \multirow{3}{*}{$\frac{\text { Model } 2 \dagger}{P \text { trend } \ddagger}$} \\
\hline & & \multicolumn{2}{|c|}{$<5$ times $(n 32)$} & \multicolumn{2}{|c|}{$5+$ times $(n 47)$} & \multirow[b]{2}{*}{$P$ trend $\ddagger$} & \\
\hline & & Mean & SE & Mean & SE & & \\
\hline Food (servings) & DG & & & & & & \\
\hline Fruit & $\geq 4$ & $1 \cdot 04$ & $0 \cdot 20$ & $1 \cdot 43$ & $0 \cdot 16$ & $0 \cdot 26$ & $0 \cdot 13$ \\
\hline Vegetables & $\geq 5$ & 1.96 & 0.46 & 2.95 & 0.37 & $0 \cdot 16$ & 0.03 \\
\hline Milk products & $\geq 3$ & $2 \cdot 04$ & $0 \cdot 42$ & $2 \cdot 23$ & 0.34 & $0 \cdot 88$ & $0 \cdot 67$ \\
\hline Whole grains & $\geq 3$ & $1 \cdot 80$ & $0 \cdot 30$ & 1.97 & 0.24 & 0.79 & $0 \cdot 39$ \\
\hline Sugar-sweetened beverages & NA & $1 \cdot 60$ & $0 \cdot 23$ & 0.84 & $0 \cdot 18$ & 0.01 & 0.03 \\
\hline Nutrients & DRI & & & & & & \\
\hline Energy (kJ) & NA & 10962 & 770 & 10054 & 619 & 0.33 & NA \\
\hline Energy (kcal) & NA & 2620 & 184 & 2403 & 148 & 0.33 & NA \\
\hline Energy from fat (\%) & $20-35 \%$ & $30 \cdot 5$ & $1 \cdot 1$ & $29 \cdot 7$ & 0.9 & 0.63 & NA \\
\hline Energy from saturated fat (\%) & $<10 \%$ & $11 \cdot 1$ & 0.5 & $10 \cdot 2$ & $0 \cdot 4$ & 0.23 & NA \\
\hline Energy from alcohol (\%) & NA & $3 \cdot 2$ & $0 \cdot 8$ & $2 \cdot 0$ & $0 \cdot 6$ & $0 \cdot 48$ & NA \\
\hline Fibre $(\mathrm{g})$ & 38 & $18 \cdot 5$ & $2 \cdot 4$ & $21 \cdot 7$ & 1.9 & 0.39 & 0.04 \\
\hline $\mathrm{Ca}(\mathrm{mg})$ & 800 & 1065 & $13 \overline{6}$ & 1171 & 109 & 0.64 & 0.22 \\
\hline $\mathrm{Fe}(\mathrm{mg})$ & $6 \cdot 0$ & $16 \cdot 9$ & $1 \cdot 7$ & $17 \cdot 6$ & $1 \cdot 3$ & 0.74 & 0.01 \\
\hline $\mathrm{K}(\mathrm{mg})$ & 4700 & 3316 & 323 & 3511 & 260 & $0 \cdot 74$ & 0.04 \\
\hline Folate $(\mu \mathrm{g}) \S$ & 320 & 601 & 83 & 821 & 67 & 0.05 & $<0.001$ \\
\hline
\end{tabular}

DG, servings recommended in the Dietary Guidelines for Americans, $2010^{(10)}$ for a $8374 \mathrm{~kJ}$ diet; NA, not applicable; DRI, Dietary Reference Intakes ${ }^{(31-35)}$ (DRI for $\mathrm{Ca}$, Fe and folate are Estimated Average Requirements; reference values for $\mathrm{K}$ and fibre are Adequate Intakes).

*Weighted Model 1 is adjusted for age, race/ethnicity, employment status, parental status, living situation and baseline frequency of family meals.

tWeighted Model 2 is adjusted for the covariates in Model 1 and total energy intake.

$\ddagger P$ value for linear trend across categories of shared meal frequency.

$\S$ As dietary folate equivalents. 
parents, frequency of shared meals was positively associated with intakes of fruit $(P=0 \cdot 01)$ and fibre $(P=0 \cdot 04)$. Among male parents, frequency of shared meals was negatively associated with intake of sugar-sweetened beverages $(P=0 \cdot 01)$.

Associations between frequency of shared meals and dietary intake were also examined in models that additionally accounted for total energy intake among female (Table 5, Model 2) and male (Table 6, Model 2) parents. Among female parents, intakes of fruit $(P=0 \cdot 01)$ and fibre $(P=0 \cdot 02)$ were still significantly and positively associated with frequency of shared meals. Among male parents, frequency of shared meals continued to be negatively associated with intake of sweetened beverages $(P=0.03)$ and was positively associated with intakes of vegetables $(P=0 \cdot 03), \mathrm{Fe}(P=0 \cdot 01), \mathrm{K}(P=0 \cdot 04)$ and folate $(P<0 \cdot 001)$. All associations remained when examined without adjustment for baseline family meal frequency, and among female parents, frequency of shared meals was also inversely associated with intake of energy from fat $(P=0 \cdot 02)$ and saturated fat $(P=0 \cdot 03)$.

\section{Discussion}

The present study described shared meal patterns and examined associations with dietary intake among a diverse population of young adults, including those who are parents. The results suggested that nearly two-thirds of young adults shared mealtimes with all or most of the people living in their household at least three times per week. Further analyses indicated that having more frequent family meals during adolescence longitudinally predicted a higher frequency of shared meals in young adulthood; this relationship was found to be independent of associations between shared meal frequency and sociodemographic characteristics of young adults, including gender, age, race, employment status, household composition and parental status. In addition, the results showed that a higher frequency of shared mealtimes in young adulthood was related to greater intakes of some healthful foods and nutrients of public health concern. Together, the 10-year longitudinal and cross-sectional findings emphasize the potential importance of establishing shared meal patterns with one's family during adolescence and supporting young adults in having more frequent shared meals in order to help them get closer to meeting national dietary recommendations. However, regardless of shared meal frequency, average young adult intakes of fruit, vegetables, milk products, whole grains, fibre and $\mathrm{K}$ fell short of national recommendations ${ }^{(10)}$.

These results support and extend prior research relating to factors that influence the frequency of shared meals. A previous study in the Project EAT sample found that having more family meals as a high-school student predicted a higher priority for social eating and meal structure five years later during late adolescence and the transition to adulthood; however, it did not examine the actual frequency of shared meals ${ }^{(43)}$. The 10 -year longitudinal design of the current study uniquely allowed for an exploration of how family meal frequency during adolescence is related to the frequency of having shared mealtimes with household members in young adulthood. The magnitude of this association was noteworthy; young adults who had seven or more family meals per week during adolescence had an average of one additional shared meal per week compared to young adults who never had family meals during adolescence. Although future research will need to confirm these findings, the results add weight to numerous prior studies that have emphasized the importance of having frequent family meals during adolescence due to observed associations with better psychosocial health, nutrition and academic outcomes $^{(6,8,40,44-46)}$.

In agreement with prior research among children and adolescents regarding the nutritional benefits of family meals ${ }^{(1-8)}$, the current study additionally observed that having shared meals in young adulthood was related to some markers of better diet quality. Having more frequent shared meals in young adulthood was associated with greater intake of fruit among males and females and with higher intakes of vegetables, milk products and key nutrients such as $\mathrm{Ca}$ among females. However, these associations appeared to be influenced in part by total energy intake, which tended to be higher among females who reported having more frequent shared meals. Although frequency of shared meals was unrelated to most markers of diet quality after accounting for differences in total energy intake, the results suggested that young adults who had more frequent shared meals tended to drink fewer sugar-sweetened beverages. Also, while fewer statistically significant associations with dietary intake were found among young adult parents, possibly due to the small size of the parent subset and limited variability in family meal frequency among this group, the results indicated that having more frequent shared meals may have supported better nutritional intake among parents. This finding is notable given that the dietary behaviours modelled by parents represent an important influence on the development of children's food preferences and eating behaviour ${ }^{(47,48)}$.

Certain strengths and limitations are important to consider in drawing conclusions from the present study. Strengths of the study included the longitudinal design and large sample of young adults who were diverse in terms of race, educational attainment, employment and parental status. The comprehensive examination of usual dietary intake using a validated FFQ was another study strength $^{(36,37)}$; however, the tool did not specifically allow for investigation of the types of foods and beverages served at shared meals. The measure of shared meals in young adulthood assessed the frequency of eating with 
all or most other household members, but no additional information was collected regarding which members were involved in preparing or purchasing meals, which members participated in meals or the mealtime environment. It is further possible that young adult participants in the current study who did not report having shared meals with household members were sharing meals on a regular basis with a partner or friends living outside their household. The observed associations with dietary intake may differ according to the living situations of young adults as it is likely that meals shared with individuals not residing in the same household are more often purchased at restaurants or cafeterias $v$. prepared at home. Some misclassification on young adults' living situation may have influenced the results due to a difference between the time period referenced in the measure of shared meals (past week) and the period referenced in the measure of living situation (past year). Finally, nonresponse at EAT-III might have produced biases not fully corrected by the use of propensity weighting. These concerns regarding non-response bias were lessened by analyses comparing responders and non-responders that showed no association between response at EAT-III and family meal frequency at baseline regardless of whether the models used propensity weights.

Results of the study indicated that having more family meals during adolescence was associated with more frequent shared meals in young adulthood. Additionally, the frequency of having shared meals in young adulthood was related to some indicators of better diet quality. Food and nutrition professionals should encourage families to share meals often and establish the tradition of eating together, and work with young adults to ensure healthy food and beverage choices are offered at mealtimes. Developing cooking skills and learning strategies for preparing quick and healthy meals may be of particular benefit to young adults employed outside the home as this demographic group was found to have fewer shared meals compared with young adults who were not employed. Only a small number of interventions have been developed to support families in sharing meals and, to the best of the authors' knowledge, no evaluated programmes have been targeted to young adults. However, published evaluations of initiatives designed to promote shared meals have suggested it may be particularly beneficial to address barriers such as lack of time or support and parenting knowledge in messages targeted to parents and to teach food preparation skills to school-aged children and adolescents so they can help with family meal planning and preparation ${ }^{(49-51)}$.

Future studies in young adult populations will be needed to confirm the results of the current study and further inform the development of programmes and services. Research should be conducted to build a better understanding of shared mealtime environments among young adults with diverse living arrangements. There is a need for exploration of hypothesized reasons why having shared meals may contribute to better dietary intake and why associations between shared meal frequency and dietary quality may be weaker during young adulthood $v$. childhood and adolescence, particularly among those who are parents. Having more frequent shared meals in young adulthood may contribute to better diet quality if social eating facilitates mindful food choices at the table or if household members are more likely to take the time to shop for and prepare healthful foods when their efforts will be shared with others; however, research is needed to confirm such potential mechanisms. As parents reported a higher average frequency of shared mealtimes than nonparents and parental modelling is key to the development of healthy eating patterns in early childhood ${ }^{(47)}$, it will be especially important to develop a better understanding of how young adults involve their children in mealtimes. Additional qualitative studies focusing on young adult populations could also build on what is known about the aspects of paid employment that are the greatest barriers to having shared mealtimes and help to identify successful coping strategies ${ }^{(52-55)}$. Finally, there is a need for studies to examine meal structure, the types of foods and beverages served at home-prepared meals and how frequently shared meals are consumed at restaurants to guide strategies for promoting healthy choices.

\section{Acknowledgements}

Sources of funding: This work was supported by grant number R01HL084064 from the National Heart, Lung, and Blood Institute (Principal Investigator: D.N.-S.). The content is solely the responsibility of the authors and does not necessarily represent the official views of the National Heart, Lung, and Blood Institute or the National Institutes of Health. Conflict of interest: The authors have no potential conflict of interest to report. Author contributions: N.L. conducted the statistical analysis and drafted the manuscript. J.F. and M.S. helped to conceptualize the analysis plan. D.N.-S. conceptualized the larger Project EAT study design and oversaw data collection. All authors contributed to the interpretation of results and manuscript revisions.

\section{References}

1. Kusano-Tsunoh A, Nakatsuka H, Satoh H et al. (2001) Effects of family-togetherness on the food selection by primary and junior high school students: family togetherness means better food. Tohoku J Exp Med 194, 121-127.

2. Haapalahti M, Mykkanen H, Tikkanen S et al. (2003) Meal patterns and food use in 10- to 11-year-old Finnish children. Public Health Nutr 6, 365-370.

3. Cooke L, Wardle J, Gibson E et al. (2004) Demographic, familial and trait predictors of fruit and vegetable consumption by pre-school children. Public Health Nutr 7, 295-302. 
4. Ayala G, Baquero B, Arredondo E et al. (2007) Association between family variables and Mexican American children's dietary behaviors. J Nutr Educ Behav 39, 62-69.

5. Crombie I, Kiezebrink K, Irvine L et al. (2009) What maternal factors influence the diet of 2-year-old children living in deprived areas? A cross-sectional survey. Public Health Nutr 12, 1254-1260.

6. Gillman M, Rifas-Shiman S, Frazier A et al. (2000) Family dinner and diet quality among older children and adolescents. Arch Fam Med 9, 235-240.

7. Videon T \& Manning C (2003) Influences on adolescent eating patterns: the importance of family meals. $J$ Adolesc Health 32, 365-373.

8. Neumark-Sztainer D, Hannan P, Story M et al. (2003) Family meal patterns: associations with sociodemographic characteristics and improved dietary intake among adolescents. J Am Diet Assoc 103, 317-322.

9. Nelson MC, Story M, Larson NI et al. (2008) Emerging adulthood and college-aged youth: an overlooked age for weight-related behavior change. Obesity (Silver Spring) 16, 2205-2211.

10. US Department of Agriculture \& US Department of Health and Human Services (2011) Dietary Guidelines for Americans, 2010. Washington, DC: US Government Printing Office; available at http://www.health.gov/ dietaryguidelines/

11. Krebs-Smith S, Guenther P, Subar A et al. (2010) Americans do not meet federal dietary recommendations. J Nutr 140, 1832-1838.

12. Moshfegh A, Goldman J \& Cleveland L (2005) What We Eat in America, NHANES 2001-2002: Usual Nutrient Intakes from Food Compared to Dietary Reference Intakes. Beltsville, MD: US Department of Agriculture, Agricultural Research Service; available at http://www.ars.usda.gov/ SP2UserFiles/Place/12355000/pdf/usualintaketables2001-02.pdf

13. Moshfegh A, Goldman J, Ahuja J et al. (2009) What We Eat in America, NHANES 2005-2006: Usual Nutrient Intakes from Food and Water Compared to 1997 Dietary Reference Intakes for Vitamin D, Calcium, Phosphorus, and Magnesium. Beltsville, MD: US Department of Agriculture, Agricultural Research Service; available at http://www. ars.usda.gov/SP2UserFiles/Place/12355000/pdf/0506/usual_ nutrient_intake_vitD_ca_phos_mg_2005-06.pdf

14. Berge J, Larson N, Bauer K et al. (2011) Are parents of young children practicing healthy nutrition and physical activity behaviors? Pediatrics 127, 881-887.

15. Neumark-Sztainer D, Story M, Hannan P et al. (2002) Overweight status and eating patterns among adolescents: where do youth stand in comparison to the Healthy People 2010 Objectives? Am J Public Health 92, 844-851.

16. Neumark-Sztainer D, Croll J, Story M et al. (2002) Ethnic/ racial differences in weight-related concerns and behaviors among adolescent girls and boys: findings from Project EAT. J Psychosom Res 53, 963-974.

17. Larson N, Neumark-Sztainer D, Harwood E et al. (2011) Do young adults participate in surveys that 'go green'? Response rates to a web and mailed survey of weight-related health behaviors. Int J Child Health Hum Dev 4, 225-237.

18. Bandura A (1986) Social Foundations of Thought and Action: A Social Cognitive Theory. Englewood Cliffs, NJ: Prentice-Hall.

19. Story M, Kaphingst K, Robinson-O'Brien R et al. (2008) Creating healthy food and eating environments: policy and environmental approaches. Annu Rev Public Health 29, 253-272.

20. Sallis J, Owen N \& Fisher E (2008) Ecological models of health behavior. In Health Behavior and Health Education: Theory, Research, and Practice, 4th ed., pp. 465-485 [K Glanz, B Rimer and K Viswanath, editors]. San Francisco, CA: Jossey-Bass.
21. Brug J, van Lenthe FJ \& Kremers S (2006) Revisiting Kurt Lewin: how to gain insight into environmental correlates of obesogenic behaviors. Am J Prev Med 31, 525-529.

22. Sallis J, Story M \& Lou D (2009) Study designs and analytic strategies for environmental and policy research on obesity, physical activity, and diet: recommendations from a meeting of experts. Am J Prev Med 36, 2 Suppl., S72-S77.

23. Huang T \& Glass T (2008) Transforming research strategies for understanding and preventing obesity. JAMA 300, 1811-1813.

24. Neumark-Sztainer D, Story M, Ackard D et al. (2000) The 'family meal': views of adolescents. J Nutr Educ Behav 32, 329-334.

25. Larson N, Neumark-Sztainer D, Story M et al. (2011) Identifying correlates of young adults' weight behavior: survey development. Am J Health Behav 35, 712-725.

26. Neumark-Sztainer D, Wall M, Story M et al. (2004) Are family meal patterns associated with disordered eating behaviors among adolescents? J Adolesc Health 35, 350-359.

27. Neumark-Sztainer D, Story M, Perry C et al. (1999) Factors influencing food choices of adolescents: findings from focus-group discussions with adolescents. J Am Diet Assoc 99, 929-937.

28. Harvard School of Public Health Nutrition Department (2012) HSPH Nutrition Department's File Download Site. https://regepi.bwh.harvard.edu/health/nutrition.html (accessed May 2012).

29. Houghton L \& O'Connor D (2008) Pregnancy and lactation. In Optimizing Women's Health through Nutrition, 1st ed., pp. 65-92 [L Thompson and W Ward, editors]. Boca Raton, FL: CRC Press.

30. US Department of Agriculture, Agricultural Research Service (2012) USDA National Nutrient Database for Standard Reference, Release 19. Nutrient Data Laboratory Home Page. http://www.ars.usda.gov/Services/docs.htm? docid $=15973$ (accessed May 2012).

31. Institute of Medicine (1998) Dietary Reference Intakes for Thiamin, Riboflavin, Niacin, Vitamin $B_{6}$, Folate, Vitamin $B_{12}$, Pantothenic Acid, Biotin, and Choline. Washington, DC: National Academy Press.

32. Institute of Medicine (2000) Reference Intakes for Vitamin C, Vitamin E, Selenium, and Carotenoids. Washington, DC: National Academy Press.

33. Institute of Medicine (2001) Dietary Reference Intakes for Vitamin A, Vitamin K, Arsenic, Boron, Chromium, Copper, Iodine, Iron, Manganese, Molybdenum, Nickel, Silicon, Vanadium, and Zinc. Washington, DC: National Academy Press.

34. Ross A, Taylor C, Yaktine A et al. (2010) Dietary Reference Intakes for Calcium and Vitamin D. Washington, DC: National Academy Press.

35. Institute of Medicine, Food and Nutrition Board (2005) Dietary Reference Intakes for Energy, Carbohydrate, Fiber, Fat, Fatty Acids, Cholesterol, Protein, and Amino Acids (Macronutrients). Washington, DC: National Academy Press.

36. Feskanich D, Rimm E, Giovannucci E et al. (1993) Reproducibility and validity of food intake measurements from a semiquantitative food frequency questionnaire. J Am Diet Assoc 93, 790-796.

37. Rimm E, Giovannucci E, Stampfer M et al. (1992) Reproducibility and validity of an expanded selfadministered semiquantitative food frequency questionnaire among male health professionals. Am J Epidemiol 135, 1114-1126.

38. Willett W. (1998) Nutritional Epidemiology, 2nd ed. New York: Oxford University Press.

39. Holt K, Wooldridge N, Story M et al. (editors) (2011) Bright Futures Nutrition, 3rd ed. Elk Grove Village, IL: American Academy of Pediatrics. 
40. Larson N, Neumark-Sztainer D, Hannan P et al. (2007) Family meals during adolescence are associated with higher diet quality and healthful meal patterns during young adulthood. J Am Diet Assoc 107, 1502-1510.

41. Willett WC, Howe GR \& Kushi LH (1997) Adjustment for total energy intake in epidemiologic studies. Am J Clin Nutr 65, 4 Suppl., 1220S-1228S.

42. Little R (1986) Survey nonresponse adjustments for estimates of means. Int Stat Rev 54, 139-157.

43. Larson N, Nelson M, Neumark-Sztainer D et al. (2009) Making time for meals: meal structure and associations with dietary intake in young adults. J Am Diet Assoc 109, 72-79.

44. Fulkerson J, Kubik M, Story M et al. (2009) Are there nutritional and other benefits associated with family meals among at-risk youth? J Adolesc Health 45, 389-395.

45. Eisenberg M, Olson R, Neumark-Sztainer D et al. (2004) Correlations between family meals and psychosocial well-being among adolescents. Arch Pediatr Adolesc Med 158, 792-796.

46. Fulkerson J, Story M, Mellin A et al. (2006) Family dinner meal frequency and adolescent development: relationships with developmental assets and high-risk behaviors. J Adolesc Health 39, 337-345.

47. Savage J, Orlet Fisher J \& Birch L (2007) Parental influence on eating behavior: conception to adolescence. I Law Med Ethics 35, 22-34.
48. Ventura A \& Birch L (2008) Does parenting affect children's eating and weight status? Int J Behav Nutr Phys Act 5, 15.

49. Rosenkranz R \& Dzewaltowski D (2009) Promoting better family meals for girls attending summer programs. J Nutr Educ Behav 41, 65-67.

50. Johnson D, Birkett D, Evens C et al. (2006) Promoting family meals in WIC: lessons learned from a statewide initiative. J Nutr Educ Behav 38, 177-182.

51. Fulkerson J, Rydell S, Kubik M et al. (2010) Healthy Home Offerings via the Mealtime Environment (HOME): feasibility, acceptability, and outcomes of a pilot study. Obesity (Silver Spring) 18, Suppl. 1, S69-S74.

52. Devine C, Stoddard A, Barbeau E et al. (2007) Workto-family spillover and fruit and vegetable consumption among construction laborers. Am J Health Promot 21, 175-182.

53. Allen T, Shockley K \& Poteat L (2008) Workplace factors associated with family dinner behaviors. J Vocat Behav $\mathbf{7 3}$, 336-342.

54. Devine C, Farrell T, Blake C et al. (2009) Work conditions and the food choice coping strategies of employed parents. J Nutr Educ Behav 41, 365-370.

55. Blake C, Devine C, Wethington E et al. (2009) Employed parents' satisfaction with food-choice coping strategies. Influence of gender and structure. Appetite 52, 711-719. 